\title{
$\alpha$-Adrenergic blockade unmasks a greater compensatory vasodilation in hypoperfused contracting muscle
}

\section{Darren P. Casey* and Michael J. Joyner}

Human and Integrative Physiology Laboratory, Department of Anesthesiology, Mayo Clinic, Rochester, MN, USA

\section{Edited by:}

Paul J. Fadel, University of Missouri, USA

\section{Reviewed by:}

Alvaro N. Gurovich, Indiana State University, USA

Dirk J. Duncker, University Medical Center Rotterdam, Netherlands Nathan T. Jenkins, University of Missouri, USA

*Correspondence:

Darren P. Casey, Department of Anesthesiology, Mayo Clinic, 200 First Street Southwest, Rochester, MN 55905, USA.

e-mail: casey.darren@mayo.edu
We previously demonstrated that acute hypoperfusion in exercising human muscle causes an immediate increase in vascular resistance that is followed by a partial restoration (less than $100 \%$ recovery) of flow. In the current study we examined the contribution of $\alpha$ adrenergic vasoconstriction in the initial changes in vascular resistance at the onset of hypoperfusion as well as in the recovery of flow over time. Nine healthy male subjects $(29 \pm 2)$ performed rhythmic forearm exercise (20\% of maximum) during hypoperfusion evoked by intra-arterial balloon inflation. Each trial included; baseline, exercise prior to inflation, exercise with inflation, and exercise after deflation ( 3 min each). Forearm blood flow (FBF; ultrasound), local (brachial artery), and systemic arterial pressure (MAP; Finometer) were measured. The trial was repeated during phentolamine infusion ( $\alpha$-adrenergic receptor blockade). Forearm vascular conductance (FVC; $\mathrm{ml} \mathrm{min}^{-1} 100 \mathrm{mmHg}^{-1}$ ) and resistance $\left(\mathrm{mmHg} \mathrm{ml} \mathrm{min}{ }^{-1}\right)$ was calculated from BF $\left(\mathrm{ml} \mathrm{min}^{-1}\right)$ and local MAP $(\mathrm{mmHg})$. Recovery of $\mathrm{FBF}$ and $\mathrm{FVC}$ (steady state inflation plus exercise value - nadir)/[steady state exercise (control) value - nadir] with phentolamine was enhanced compared with the respective control (no drug) trial (FBF $=97 \pm 5 \%$ vs. $81 \pm 6 \%, P<0.05 ; F V C=126 \pm 9 \%$ vs. $91 \pm 5 \%$, $P<0.01)$. However, the absolute $\left(0.05 \pm 0.01\right.$ vs. $\left.0.06 \pm 0.01 \mathrm{mmHg} \mathrm{ml} \mathrm{min}^{-1} ; P=0.17\right)$ and relative ( $35 \pm 5 \%$ vs. $31 \pm 2 \% ; P=0.41$ ) increase in vascular resistance at the onset of balloon inflation was not different between the $\alpha$-adrenergic receptor inhibition and control (no drug) trials. Therefore, our data indicate that $\alpha$-adrenergic mediated vasoconstriction restricts compensatory vasodilation during forearm exercise with hypoperfusion, but is not responsible for the initial increase in vascular resistance at the onset of hypoperfusion.

Keywords: alpha-adrenergic receptors, vascular resistance, blood flow, exercise, hypoperfusion

\section{INTRODUCTION}

In animals, when blood flow is restricted and/or perfusion pressure is reduced, the active muscle is capable of autoregulating its blood flow (Stainsby, 1962; Jones and Berne, 1964; Britton et al., 1985; Metting et al., 1986) via intrinsic control mechanisms (Jones and Berne, 1964; Britton et al., 1985). Additionally, a reflex pressor response contributes to the restoration of blood flow to under perfused exercising muscle in dogs (Wyss et al., 1983; Sheriff et al., 1987; Mittelstadt et al., 1994; O'leary and Sheriff, 1995; Laprad et al., 1999). Using a novel balloon catheter model in the brachial artery to reduce blood flow to contracting forearm muscles, we previously demonstrated that local vasodilator and/or myogenic mechanisms, rather than a pressor response, are responsible for a substantial portion of the restoration of flow to hypoperfused exercising human muscle (Casey and Joyner, 2009b). In subsequent studies we found that nitric oxide- and adenosine-, but not prostaglandin-, mediated vasodilation play a substantial role in the compensatory flow response to hypoperfusion (Casey and Joyner, 2009a, 2011a,c).

Collectively, our series of studies (Casey and Joyner, 2009a,b, $2011 \mathrm{a}, \mathrm{c})$ demonstrated that there is only partial compensation of flow $(<100 \%$ recovery) in response to local reductions in oxygen availability via hypoperfusion. This is in contrast to other conditions in which oxygen availability is decreased (e.g., hypoxia and anemia). Under these conditions there is a compensatory vasodilation that mirrors the decrease in oxygen content (Gonzalez-Alonso et al., 2006; Wilkins et al., 2006; Casey et al., 2010). Interestingly, our hypoperfusion studies also revealed an initial increase in vascular resistance in the forearm at the onset of balloon inflation that progressively decreases over the inflation period. The initial rise in vascular resistance in these studies is in contrast to the classic view of autoregulation (a decrease in perfusion pressure is followed by a reduction in resistance to blood flow through the muscle; Stainsby, 1962; Granger et al., 1976; Britton et al., 1985; Ping and Johnson, 1992). However, the initial increase in vascular resistance is not unprecedented in that an immediate increase in vascular resistance has also been reported to occur in isolated perfused skeletal muscle of dogs (Jones and Berne, 1964). The reason for the initial increase in vascular resistance at the onset of balloon inflation and the incomplete restoration over time is not fully understood. Of interest to the current study, Daley et al. (2003) demonstrated that an increase in muscle sympathetic nerve activity (MSNA) can blunt the restoration of flow to hypoperfused exercising muscle induced by external positive pressure. An increased sympathetic restraint in the microcirculation distal to a stenosis of a proximal artery may have clinical implications as it suggests that conditions with elevated MSNA might be more susceptible to hypoperfusion and ischemia during exercise. Therefore, the aim of this study was to 
examine the contribution of $\alpha$-adrenergic vasoconstriction in the initial changes in vascular resistance at the onset of hypoperfusion as well as in the recovery of flow over time.

\section{MATERIALS AND METHODS SUBJECTS}

A total of nine young healthy male subjects volunteered to participate in the study. Subjects gave written informed consent and were non-obese, non-smokers, and were not taking any medications. Studies were performed after an overnight fast and after the subjects refrained from exercise and caffeine for at least $24 \mathrm{~h}$. All study protocols were approved by Institutional Review Board and in accordance with the Declaration of Helsinki. Other data collected in this set of subjects has been previously reported by our group (Casey and Joyner, 2009b).

\section{HEART RATE AND SYSTEMIC BLOOD PRESSURE}

Heart rate (HR) was measured by three-lead electrocardiography (ECG). Systemic blood pressure was assessed (beat-to-beat) with a finger plethysmograph (Finometer) on the non-exercising hand and verified with an automated cuff on the same arm. The systemic pressure was used as an index of pressure proximal (upstream) from the balloon. Cardiac output (CO) was estimated using the Modelflow technique which has been validated against other techniques and used in exercise studies (Wesseling et al., 1993; Ogoh et al., 2003).

\section{ARTERIAL CATHETERIZATION AND BALLOON PLACEMENT}

Brachial catheter placement and balloon insertion has been described in detail previously (Casey and Joyner, 2009b). Briefly, a 20 -gage, $5 \mathrm{~cm}$ catheter was placed in the brachial artery in the experimental arm using ultrasound guidance under aseptic conditions after local anesthesia (2\% lidocaine). A guide wire was then placed in the artery which was then cannulated with a four-French introducer (Cook Inc., Bloomington, IN, USA) that permitted insertion of a two-French Fogarty balloon catheter into the brachial artery. A port and stopcock system allowed the measurement of arterial pressure, administration of study drugs and drawing of arterial blood samples. The system was continuously flushed $\left(3 \mathrm{ml} \mathrm{h}^{-1}\right)$ with heparinized saline. The configuration of the balloon upstream from the lumen of the introducer allowed measurement of the arterial pressure distal to the balloon that was perfusing the contracting forearm muscles.

\section{FOREARM BLOOD FLOW}

Brachial artery mean blood velocity (MBV) and brachial artery diameter were determined with a $12 \mathrm{MHz}$ linear-array Doppler probe (Model M12L, Vivid 7, General Electric, Milwaukee, WI, USA). Brachial artery blood velocity was measured throughout each condition with a probe insonation angle previously calibrated to $60^{\circ}$. Brachial artery and balloon diameter measurements were obtained at end diastole and between contractions during steadystate conditions. Diameter measurement typically results in the loss of the pulse wave signal for 15-20 s. Therefore, brachial artery diameters were not obtained for the target balloon inflation (nadir) and the first $10 \mathrm{~s}$ immediately following balloon deflation (acute) portions of the trial. The diameters obtained immediately prior to each of these time points were used to calculate blood flow. It should be noted that we have previously demonstrated that the brachial artery diameter does not change in response to inflation and deflation of the balloon at rest and during exercise (Casey and Joyner, 2009b). Velocity and diameter measurements were made $2-3 \mathrm{~cm}$ proximal to the balloon. FBF was calculated as the product of $\mathrm{MBV}\left(\mathrm{cm} \mathrm{s}^{-1}\right)$ and brachial artery cross-sectional area $\left(\mathrm{cm}^{2}\right)$ and multiplied by 60 to present as milliliters per minute.

\section{FOREARM EXERCISE}

Rhythmic forearm exercise was performed with a hand grip device by the non-dominant arm at $20 \%$ of each subject's maximal voluntary contraction (MVC, mean $49 \pm 2 \mathrm{~kg}$, range $43-58 \mathrm{~kg}$ ). The weight was lifted $4-5 \mathrm{~cm}$ over a pulley at a duty cycle of $1 \mathrm{~s}$ contraction/and $2 \mathrm{~s}$ relaxation (20 contractions per min) using a metronome to insure correct timing. The average weight used for forearm exercise was $9.9 \pm 0.4 \mathrm{~kg}$.

\section{BRACHIAL ARTERY BALLOON INFLATION}

To reduce FBF the brachial artery was partially occluded via inflation of the Fogarty balloon catheter with saline using a calibrated microsyringe for tight control of balloon volume. Balloon inflations were targeted to reduce MBV by $40-50 \%$.

\section{PHARMACOLOGICAL INFUSIONS}

Phentolamine, a non-selective $\alpha$-adrenergic antagonist, was administered to the exercising forearm via brachial artery catheter as a loading dose $[10 \mu \mathrm{g} \text { ( } \mathrm{dl} \text { forearm volume })^{-1} \mathrm{~min}^{-1}$ for $5 \mathrm{~min}$ ] followed by a continuous maintenance dose $\left(50 \mu \mathrm{g} \mathrm{min}^{-1}\right)$. To confirm $\alpha$-adrenergic receptor blockade, tyramine was administered $[12 \mu \mathrm{g} \text { (dl forearm volume })^{-1} \mathrm{~min}^{-1}$ for $3 \mathrm{~min}$ ] to evoke endogenous norepinephrine release and stimulate both $\alpha_{1}$ - and $\alpha_{2}$-adrenergic receptors before and after phentolamine (Frewin and Whelan, 1968; Dinenno et al., 2002a,b).

\section{EXPERIMENTAL PROTOCOL}

A schematic of the general experimental design is illustrated in Figure 1. Each subject completed a control (no drug) and an $\alpha$ adrenergic blockade (phentolamine) trial. Each trial consisted of 3 min of rest, exercise, exercise with balloon inflation, exercise following balloon deflation, and recovery ( $15 \mathrm{~min}$ total; $9 \mathrm{~min}$ of total exercise). The phentolamine trials were always performed last due to the drug's half-life. Each trial was separated by $20 \mathrm{~min}$ of rest to allow FBF to return to baseline.

\section{DATA ANALYSIS AND STATISTICS}

Data were collected at $200 \mathrm{~Hz}$, stored on a computer and analyzed off-line with signal processing software (WinDaq, DATAQ Instruments, Akron, OH, USA). Local mean arterial pressure (BAP) was determined from the brachial artery pressure waveform measured distal to the balloon, systemic MAP (e.g., pressure proximal to the balloon) was derived from the Finometer pressure waveform, and $\mathrm{HR}$ was determined from the electrocardiogram. FBF, BAP, $\mathrm{MAP}, \mathrm{CO}$, and $\mathrm{HR}$ were determined by averaging values during the last $30 \mathrm{~s}$ of rest, exercise, exercise with inflation, exercise following deflation, and recovery. In addition, all values were analyzed and averaged during the first $10 \mathrm{~s}$ of target balloon inflation (nadir) 


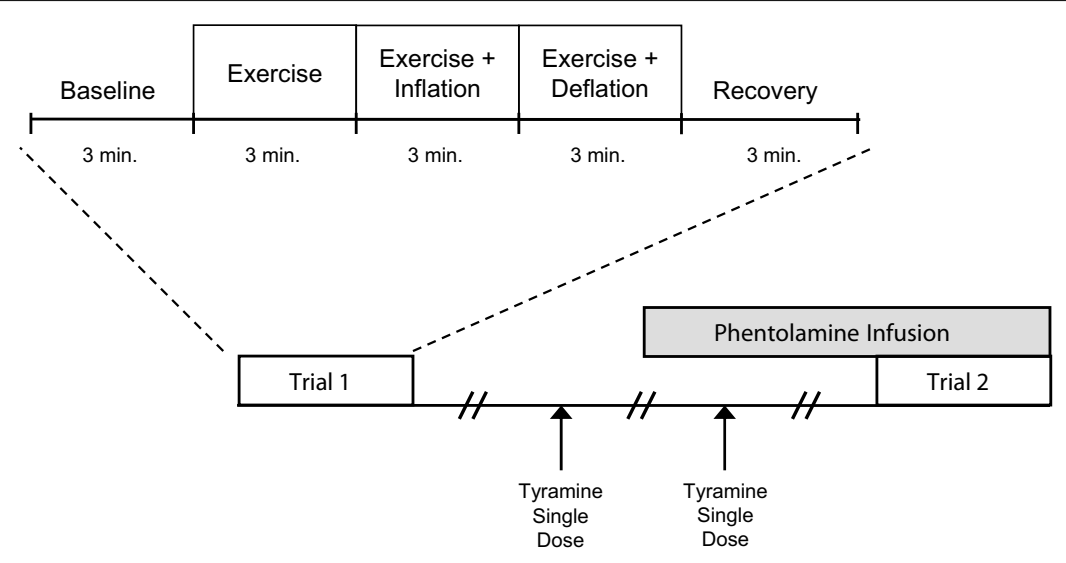

FIGURE 1 | Schematic diagram of experimental protocol. Subjects completed two trials. Each trial consisted of baseline, exercise (control), exercise during inflation, exercise following deflation, and recovery measurements ( 3 min each). Trials were performed during control (no drug) and $\alpha$-adrenergic receptor blockade (phentolamine). Each trial was separated by at least $20 \mathrm{~min}$ of rest to allow FBF to return to baseline values. Tyramine was infused with and without phentolamine to confirm the effectiveness of $\alpha$-adrenergic blockade. and the first $10 \mathrm{~s}$ immediately following balloon deflation. FVC was calculated as $(\mathrm{FBF} / \mathrm{BAP}) \times 100$ and expressed as $\mathrm{ml} \mathrm{min}^{-1}$ $\left(100 \mathrm{mmHg}^{-1}\right.$.

All values are expressed as means $\pm \mathrm{SE}$. Within a given protocol, the FBF, FVC, BAP, systemic MAP, HR, and CO during rest, exercise, the nadir after balloon inflation, exercise at the end of the balloon inflation, exercise following deflation, and recovery were analyzed by repeated measures analysis of variance (ANOVA). When significance was detected, Tukey's post hoc test was used to identify individual differences and adjust $P$ values to account for multiple comparisons, to preserve an overall type I error rate of 0.05 .

Percent recovery in FBF and FVC were calculated (steady state inflation plus exercise value - nadir)/[steady state exercise (control) value - nadir]. To investigate the contribution of $\alpha$ adrenergic vasoconstriction on percentage recovery of blood flow and conductance, paired $t$-tests were performed between drug conditions (with and without phentolamine). To further explore the contribution of local vasodilation to any restoration of flow, we analyzed balloon resistance and forearm vascular resistance and considered them individually and in series (O'leary and Sheriff, 1995; Casey and Joyner, 2009a,b). Using systemic arterial pressure (SAP; Finometer), brachial artery pressure distal to the balloon (BAP; catheter) and brachial artery blood flow, we calculated the resistance of the balloon ( $\mathrm{SAP}-\mathrm{BAP} /$ flow) and vascular resistance (BAP/flow). The total resistance was calculated as the sum of these two resistors. Changes in vascular and balloon resistance were analyzed from the onset of balloon inflation (nadir) until the end of the inflation period and expressed as a percentage change. One way repeated measures ANOVA were used to compare the percentage change in resistance between drug conditions. Statistical significance was set a priori at $P<0.05$. Statistical analyses were performed with SigmaStat 2.03 (SPSS, Inc.).

\section{RESULTS}

Eight of the nine subjects completed both of the exercise trials. One subject did not complete the entire protocol due to technical difficulties associated with the balloon during the phentolamine trial and was excluded from the analysis. Those subjects included in the group analysis were $29 \pm 2$ years of age, $180 \pm 2 \mathrm{~cm}$ in height, and weighed $82 \pm 4 \mathrm{~kg}$ (BMI: $25 \pm 1 \mathrm{~kg} \mathrm{~m}^{-2}$ ).

\section{FOREARM BLOOD FLOW AND VASODILATION DURING EXERCISE WITH BALLOON INFLATION}

Group mean data for FBF and FVC responses are presented in Table 1. As expected, exercise increased FBF and FVC in both exercise trials $(P<0.01)$. Balloon inflation (nadir) during the exercise trial with no drug acutely reduced FBF by $38 \%$ and FVC by $26 \%(P<0.001)$. FBF and FVC at the end of inflation were partially restored to exercise (control) levels, which were substantially higher than their respective nadir values $(P<0.001)$. The percentage recovery of FBF and FVC during the exercise trials are presented in Figures 2A,B.

\section{IMPACT OF $\alpha$-ADRENERGIC RECEPTOR BLOCKADE ON BLOOD FLOW RECOVERY DURING HYPOPERFUSION}

Infusion of phentolamine increased FBF and FVC throughout the entire exercise trial compared to the control (no drug) trial $(P<0.01-0.05$; Table 1). Balloon inflation (nadir) during the exercise trial with phentolamine acutely reduced $\mathrm{FBF}$ by $45 \%$ and FVC by $28 \%(P<0.001)$. The FBF and FVC at the end of inflation under $\alpha$-adrenergic receptor blockade were greater than the values observed during the no drug trial $(P<0.01$; Table 1). Consequently, the percentage recovery of FBF and FVC during the trial with phentolamine were substantially greater than the percentage recovery values observed during the no drug trial (Figures 2A,B). The time to reach steady state FBF during balloon inflation was similar between the no drug and phentolamine trials ( $49 \pm 5$ vs. $47 \pm 4$ s; $P=0.48)$.

Acute balloon inflation caused similar increases in absolute $\left(0.06 \pm 0.01\right.$ vs. $\left.0.05 \pm 0.01 \mathrm{mmHg} \mathrm{ml} \mathrm{min}^{-1} ; \quad P=0.17\right)$ and relative $(31 \pm 2 \%$ vs. $35 \pm 5 \% ; \quad P=0.41)$ vascular resistance between the no drug and phentolamine trials. Vascular resistance during balloon inflation (from nadir to 
Table 1 | Forearm blood flow and vasodilation during exercise with balloon inflation.

\begin{tabular}{|c|c|c|c|c|c|c|}
\hline & Baseline & $\begin{array}{l}\text { Exercise } \\
\text { (control) }\end{array}$ & $\begin{array}{l}\text { Inflation } \\
\text { (nadir) }\end{array}$ & $\begin{array}{l}\text { Inflation } \\
\text { (steady state) }\end{array}$ & $\begin{array}{l}\text { Deflation } \\
\text { (acute) }\end{array}$ & $\begin{array}{l}\text { Deflation } \\
\text { (steady state) }\end{array}$ \\
\hline \multicolumn{7}{|l|}{$20 \%$ MVC (NO DRUG) } \\
\hline 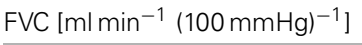 & $107 \pm 27$ & $520 \pm 42 *$ & $385 \pm 28^{* \dagger}$ & $510 \pm 44^{* \ddagger}$ & $558 \pm 56^{* \neq}$ & $558 \pm 47^{* \ddagger}$ \\
\hline \multicolumn{7}{|l|}{$20 \%$ MVC (PHENTOLAMINE) } \\
\hline $\mathrm{FBF}\left(\mathrm{ml} \mathrm{min}^{-1}\right)$ & $328 \pm 36^{a}$ & $657 \pm 70 * a$ & $383 \pm 49^{\dagger b}$ & $642 \pm 70^{* \neq a}$ & $755 \pm 88^{* \neq \S a}$ & $685 \pm 75^{* \neq a}$ \\
\hline
\end{tabular}

Values are means $\pm S E$. FBF, forearm blood flow; FVC, forearm vascular conductance; MVC, maximal voluntary contraction. ${ }^{*} P<0.01$ vs. baseline; ${ }^{t} P<0.001$ vs. exercise (control); ${ }^{\ddagger} P<0.001 \mathrm{vs}$. nadir; ${ }^{s} P<0.05$ vs. inflation (steady state); ${ }^{a} P<0.01 \mathrm{vs}$. no drug trial; ${ }^{b} P<0.05$ vs. no drug trial.

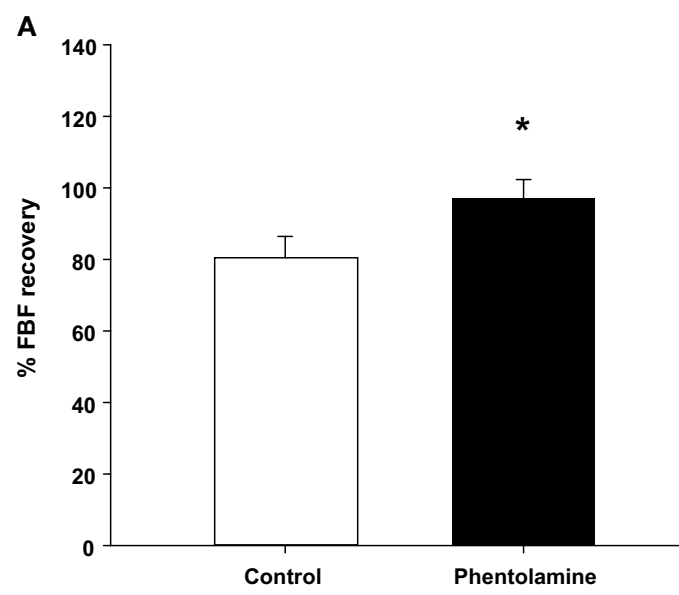

FIGURE 2 | Percentage recovery in forearm blood flow [FBF; (A)] and forearm vascular conductance [FVC; (B)] during balloon

inflation. The percentage recovery in FBF and FVC was enhanced

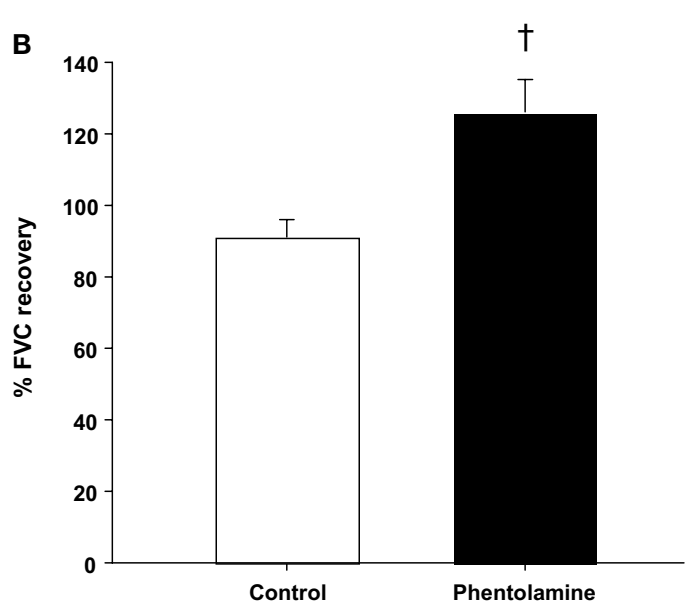

under local $\alpha$-adrenergic blockade during exercise with hypoperfusion. ${ }^{*} P<0.05$ vs. control (no drug); ${ }^{\dagger} P<0.01$ vs. control (no drug). end of inflation) decreased during the no drug $(0.27 \pm 0.02$ vs. $\left.0.21 \pm 0.02 \mathrm{mmHg} \mathrm{ml} \mathrm{min}^{-1} ; P<0.001\right)$, and phentolamine $\left(0.20 \pm 0.02\right.$ vs. $\left.0.14 \pm 0.02 \mathrm{mmHg} \mathrm{ml} \mathrm{min}^{-1} ; P<0.01\right)$ trials. Although the absolute reduction in vascular resistance was similar between trials $(P=0.76)$, the percentage reduction in vascular resistance was greater with phentolamine $(-31 \pm 2 \%$ vs. $-24 \pm 2 \%$; $P<0.01$ vs. no drug trial). Balloon resistance decreased (from nadir to end of inflation) in the no drug $\left(0.05 \pm 0.01\right.$ vs. $\left.0.02 \pm 0.01 \mathrm{mmHg} \mathrm{ml} \mathrm{min}^{-1} ; \quad P<0.01\right)$ and phentolamine $\left(0.05 \pm 0.01\right.$ vs. $0.03 \pm 0.01 \mathrm{mmHg} \mathrm{ml} \mathrm{min}^{-1}$; $P<0.01)$ trails. However the absolute $(-0.03 \pm 0.01$ vs. $-0.03 \pm 0.01 ; P=0.93)$ and relative $(-50 \pm 8 \%$ vs. $-49 \pm 4 \%$; $P=0.91)$ changes in balloon resistance were not different between drug conditions.

\section{EFFECT OF $\alpha$-ADRENERGIC RECEPTOR BLOCKADE ON VASCULAR RESPONSES TO EXOGENOUS TYRAMINE}

Tyramine caused a substantial reduction in FVC ( $87 \pm 26$ vs. $\left.124 \pm 25 \mathrm{ml} \mathrm{min}^{-1}(100 \mathrm{mmHg})^{-1} ; \quad P<0.001\right) . \alpha$-Adrenergic receptor blockade with phentolamine prevented a significant vasoconstrictor response to tyramine $\left(300 \pm 33\right.$ vs. $318 \pm 34 \mathrm{ml} \mathrm{min}^{-1}$ $\left.(100 \mathrm{mmHg})^{-1} ; \quad P=0.16\right)$. The relative tyramine-induced reductions in FVC (with and without phentolamine) are presented in Figure 3.

\section{VASOCONSTRICTOR RESPONSIVENESS AND BLOOD FLOW RECOVERY DURING HYPOPERFUSION}

Figure 4 illustrates a strong relationship between the vasoconstrictor responsiveness to endogenous norepinephrine release via infusion of tyramine and the percentage FBF recovery during forearm exercise with hypoperfusion. Subjects with greater vasoconstrictor responsiveness to tyramine (i.e., greater reduction in FBF) demonstrated a lower percentage FBF recovery.

\section{HEMODYNAMIC CHANGES}

Systemic hemodynamic responses during exercise are presented in Table 2. Exercise resulted in an increase in MAP in both control (no drug) and phentolamine trials $(P<0.05)$. MAP remained elevated above baseline values throughout each trial $(P<0.05)$. Estimated $\mathrm{CO}$ did not change with exercise (control) compared to baseline in either trail, despite a slight increase in HR during the control (no drug) trial. Compared to baseline values $\mathrm{CO}$ was elevated during balloon inflation and deflation in the control (no drug trial), whereas it was only elevated during the deflation period in 


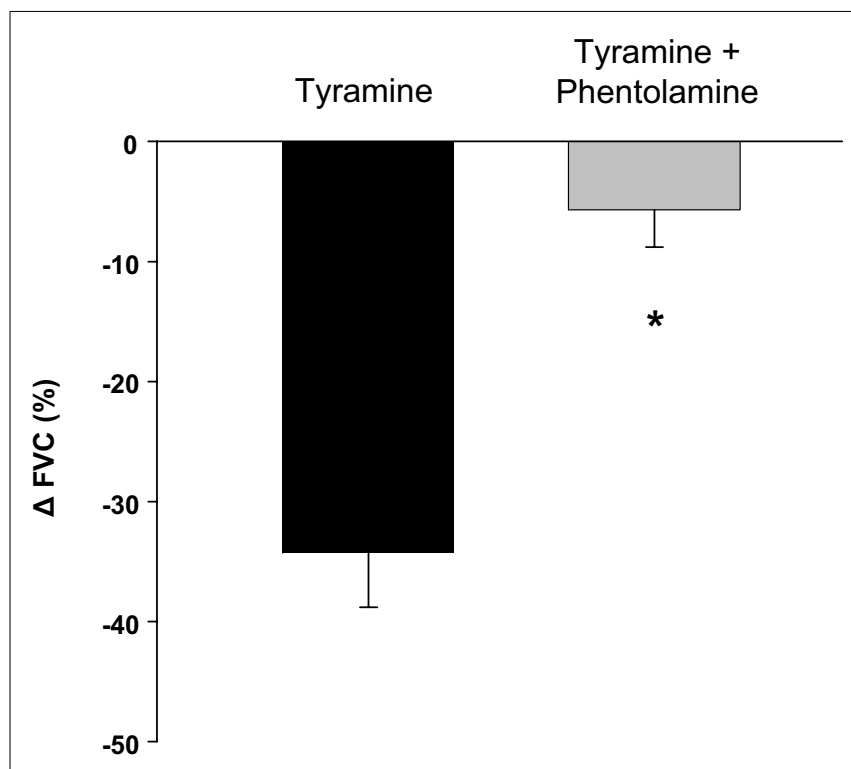

FIGURE 3 | Effectiveness of phentolamine in blocking $\alpha$-adrenergic vasoconstriction. $\alpha$-Adrenergic blockade via phentolamine substantially reduced the vasoconstrictor responsiveness ( $\Delta$ forearm vascular conductance; FVC) to tyramine. ${ }^{*} P<0.001$ vs. control (no drug).

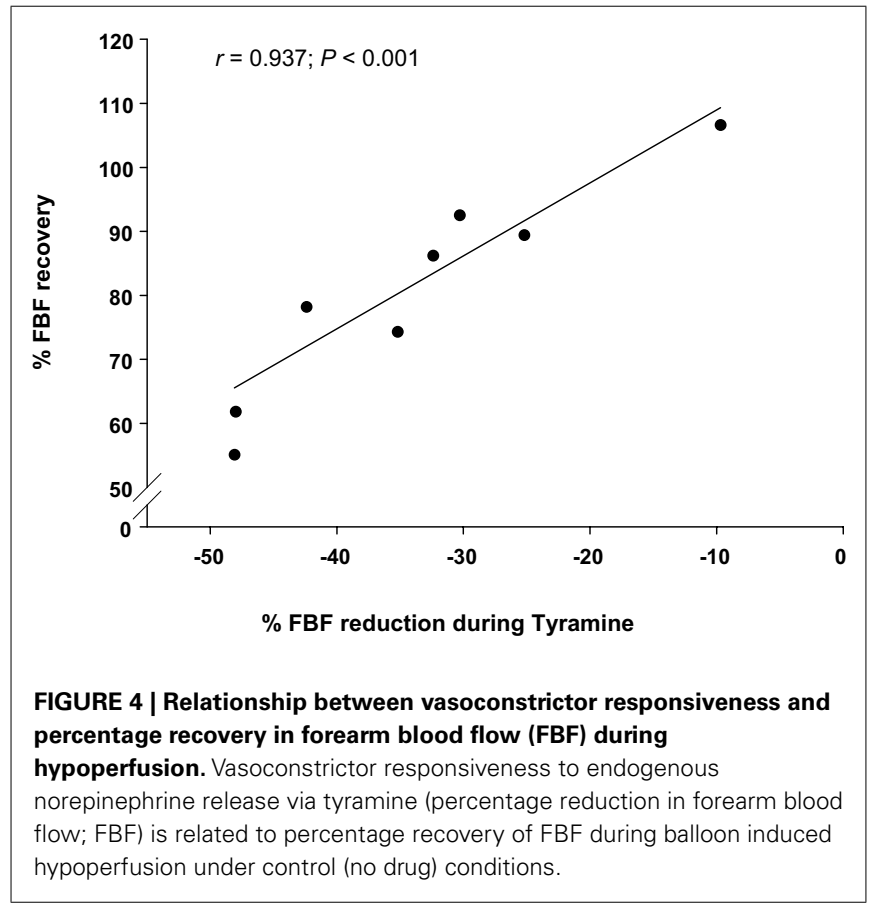

the phentolamine trial $(P<0.05)$. Important to the present study, $\mathrm{MAP}, \mathrm{HR}$, and $\mathrm{CO}$ did not change with balloon inflation compared to exercise (control) values in either trail.

\section{DISCUSSION}

The novel findings of our study are (1) $\alpha$-adrenergic blockade unmasks a greater compensatory vasodilation and flow recovery to hypoperfused contracting muscle, (2) the initial increase in vascular resistance at the onset of balloon inflation does not appear to be $\alpha$-adrenergic mediated, and (3) vasoconstrictor responsiveness to endogenous norepinephrine is related to a lower flow recovery during exercise with hypoperfusion.

Stimulation of chemosensitive afferents in contracting muscle can elicit marked increases in MSNA to resting and active muscle (Mark et al., 1985; Savard et al., 1987; Victor et al., 1987, 1988). The increase in MSNA is further enhanced in hypoperfused and/or partially ischemic contracting human muscle (Michikami et al., 2000; Daley et al., 2003). Theoretically, the enhanced sympathetic drive to the muscle and subsequent vasoconstriction could limit blood flow to the active tissue. In the present study we examined whether $\alpha$-adrenergic vasoconstriction restrained flow during exercise with hypoperfusion and possibly explained the incomplete compensatory flow response $(<100 \%$ recovery) commonly observed in our studies (Casey and Joyner, 2009a,b, $2011 \mathrm{a}, \mathrm{c})$. Our data demonstrate that $\alpha$-adrenergic blockade unmasks a substantial vasodilation and restores blood flow to pre-inflation levels when compared to control trials ( $97 \%$ vs. $80 \%$ recovery, respectively; Figure 2). These findings suggest that sympathetic outflow during concurrent exercise and hypoperfusion partially limits the compensatory vasodilation in the human forearm.

Interestingly, there is an absence of a significant pressor response (above exercise alone) in our model of hypoperfusion (Table 2), thus suggesting that balloon inflation and subsequent hypoperfusion likely did not result in greater sympathetic outflow when compared to free flow exercise conditions. Therefore, it may be possible that the $\alpha$-adrenergic restraint observed with hypoperfusion may be due to an exaggerated $\alpha$-adrenergic receptor responsiveness in the partially ischemic tissue. Along these lines, the relative vasoconstriction produced by $\alpha$-adrenergic activity in the coronary circulation of dogs during exercise is greater during hypoperfusion (Laxson et al., 1989) than during normal arterial inflow (Bache et al., 1988). It is also possible that an attenuated functional sympatholysis might exist in the contracting muscle when blood flow and oxygen delivery are compromised. However, previous data form our group did not provide any evidence for reduced vasoconstrictor responsiveness (augmented functional sympatholysis) during hypoxic exercise (Wilkins et al., 2006).

Similar to our previous studies, vascular resistance increased at the onset of balloon inflation. The findings of the present study suggest that an enhanced $\alpha$-adrenergic vasoconstriction at the onset of balloon inflation does not explain the initial increase in vascular resistance. In this context, $\alpha$-adrenergic blockade did not prevent the initial rise in vascular resistance when expressed as absolute or relative changes. Although the reasons for the acute increase in vascular resistance at the onset of balloon inflation in our model of hypoperfusion are not completely clear it may be related to dampening of pulsatile flow by balloon inflation. Along these lines, pulsatile flow has been suggested to be a critical component for the release of endothelium-derived vasodilators (Rubanyi et al., 1986). Another possible explanation is that a sudden drop in perfusion pressure causes resistance vessels to recoil before autoregulatory vasodilation, a response that has been observed during mild exercise in dogs (Koch et al., 1991). Lastly, alterations in vascular bed compliance at the onset of balloon inflation may 
Table 2 | Systemic hemodynamic responses $(n=8)$.

\begin{tabular}{|c|c|c|c|c|c|c|}
\hline & Baseline & $\begin{array}{l}\text { Exercise } \\
\text { (control) }\end{array}$ & $\begin{array}{l}\text { Inflation } \\
\text { (nadir) }\end{array}$ & $\begin{array}{l}\text { Inflation } \\
\text { (steady state) }\end{array}$ & $\begin{array}{l}\text { Deflation } \\
\text { (acute) }\end{array}$ & $\begin{array}{l}\text { Deflation } \\
\text { (steady state) }\end{array}$ \\
\hline \multicolumn{7}{|l|}{$20 \%$ (CONTROL) } \\
\hline Mean arterial pressure $(\mathrm{mmHg})$ & $93 \pm 3$ & $98 \pm 4^{*}$ & $99 \pm 4^{*}$ & $100 \pm 4^{*}$ & $100 \pm 4^{*}$ & $99 \pm 4^{*}$ \\
\hline Brachial artery pressure $(\mathrm{mmHg})$ & $90 \pm 2$ & $91 \pm 3$ & $79 \pm 3^{* \ddagger}$ & $86 \pm 2^{\dagger \ddagger}$ & $91 \pm 2^{\dagger}$ & $89 \pm 2^{\dagger}$ \\
\hline Heart rate (beats $\min ^{-1}$ ) & $66 \pm 2$ & $68 \pm 2^{*}$ & $68 \pm 2^{*}$ & $68 \pm 2^{*}$ & $68 \pm 2^{*}$ & $68 \pm 2^{*}$ \\
\hline Cardiac output $\left(\mid \mathrm{min}^{-1}\right)$ & $4.8 \pm 0.3$ & $5.2 \pm 0.4$ & $5.3 \pm 0.4^{*}$ & $5.3 \pm 0.3^{*}$ & $5.4 \pm 0.4^{*}$ & $5.5 \pm 0.4^{*}$ \\
\hline \multicolumn{7}{|l|}{ 20\% (PHENTOLAMINE) } \\
\hline Mean arterial pressure $(\mathrm{mmHg})$ & $93 \pm 4$ & $97 \pm 3^{*}$ & $98 \pm 3^{*}$ & $100 \pm 3^{*}$ & $99 \pm 3^{*}$ & $101 \pm 3^{*}$ \\
\hline Brachial artery pressure $(\mathrm{mmHg})$ & $88 \pm 2$ & $90 \pm 2$ & $70 \pm 2^{* \ddagger}$ & $78 \pm 3^{* \dagger \ddagger}$ & $90 \pm 2^{\dagger}$ & $91 \pm 2^{\dagger}$ \\
\hline Heart rate (beats $\mathrm{min}^{-1}$ ) & $67 \pm 2$ & $68 \pm 2$ & $68 \pm 2$ & $68 \pm 2$ & $68 \pm 2$ & $68 \pm 2$ \\
\hline Cardiac output (I $\left.\min ^{-1}\right)$ & $5.1 \pm 0.3$ & $5.4 \pm 0.4$ & $5.5 \pm 0.4$ & $5.5 \pm 0.5$ & $5.6 \pm 0.5^{*}$ & $5.7 \pm 0.5^{*}$ \\
\hline
\end{tabular}

Values are means $\pm S E ;{ }^{*} P<0.05$ vs. baseline; ${ }^{\dagger} P<0.05$ vs. nadir; ${ }^{\ddagger} P<0.05$ vs. exercise (control).

also contribute to the acute increase in vascular resistance observed in our model of hypoperfusion (Zamir et al., 2007).

In the current study we observed an extremely strong relationship between the vasoconstrictor responsiveness to endogenous norepinephrine release (via tyramine) and ability to restore blood flow to the contracting muscle during exercise with hypoperfusion (Figure 4). That is an individual with greater vasoconstrictor responses to endogenous norepinephrine release demonstrated a blunted recovery of flow during the period of exercise with balloon inflation. This relationship suggests that the $\alpha$-adrenergic tone of the resistance vasculature in the forearm may play an important role in the ability to compensate and restore blood flow to underperfused skeletal muscle during exercise.

\section{EXPERIMENTAL CONSIDERATIONS}

The use of a non-specific $\alpha$-adrenergic antagonist (phentolamine) in the current study did not allow us to discern the relative roles of $\alpha_{1}$ - and $\alpha_{2}$-adrenergic receptors in the restriction of compensatory vasodilation during forearm exercise with hypoperfusion. In young healthy men $\alpha_{2}$-adrenergic receptors have a greater contribution to basal forearm vascular tone compared to $\alpha_{1}$-adrenergic receptors (Dinenno et al., 2002b). However, in the coronary circulation of dogs, $\alpha_{1}$ - but not $\alpha_{2}$-adrenergic mediated vasoconstriction limits blood flow distal to a coronary artery stenosis (Laxson et al., 1989). Therefore, it is unclear whether $\alpha_{1}$ and $\alpha_{2}$-adrenergic mechanisms contribute differently to the vasoconstrictor restraint of flow during exercise with hypoperfusion in humans.

Administration of phentolamine altered baseline blood flow and the absolute blood flow responses to the exercise. It could be argued that these changes in flow before balloon inflation may explain the enhanced flow recovery following $\alpha$ adrenergic blockade. However, the use of percent recovery (steady state inflation plus exercise value - nadir)/[steady state exercise (control) value - nadir] in the comparison between drug trials clearly accounts for the differences in flow before balloon inflation. Additionally, the reduction in flow caused by balloon inflation still evoked compensatory vasodilation suggesting that a metabolic error signal was present in spite of the higher flow.
Our series of experiments (Casey and Joyner, 2009a,b, 2011a,c) have consistently demonstrated that there is only a partial recovery of $\mathrm{FBF}(<100 \%)$ during exercise with acute hypoperfusion and this response is variable between subjects (see Figure 4 from Casey and Joyner, 2011b). However, the percentage FVC recovery tends to be greater than the percentage FBF recovery and in some cases reaches and/or exceeds 100\% (Casey and Joyner, 2011a). In the current study the FVC recovery during the control trial was $91 \%$, which was less than previously reported (Casey and Joyner, $2011 \mathrm{a}, \mathrm{c})$. The discrepancies in percentage FVC recovery between studies might be related to the extent of collateral channels in the forearm and magnitude of the restoration of distal perfusion pressure in the subjects of each study. Despite the somewhat lower percentage FVC recovery under control conditions in the current study there was a substantial improvement during phentolamine administration and supports the notion that $\alpha$-adrenergic vasoconstriction limits compensatory vasodilation and flow recovery to hypoperfused contracting muscle.

\section{CONCLUSION}

This study demonstrates that $\alpha$-adrenergic mediated vasoconstriction restricts compensatory vasodilation and flow during forearm exercise with hypoperfusion. However, the initial rise in vascular resistance at the onset of hypoperfusion via balloon inflation is not explained by an enhanced $\alpha$-adrenergic vasoconstriction. Taken together our findings suggest that $\alpha$-adrenergic mediated vasoconstriction plays an important role in the "less than perfect" compensatory flow response. Moreover, our data raise the concern that patients with enhanced $\alpha$-adrenergic vasoconstrictor responsiveness might be more at risk to ischemia during exercise, especially in vascular regions distal to a stenosis.

\section{ACKNOWLEDGMENTS}

We thank Branton Walker, Shelly Roberts, Jean Knutson, Karen Krucker, Chistopher Johnson, and Pam Engrav for their technical assistance. We also thank the volunteers for their time. This study was supported by the National Institutes of Health research grants HL-46493 (to Michael J. Joyner), AR-55819 (to Darren P. Casey) and by CTSA RR-024150. The Caywood Professorship via the Mayo Foundation also supported this research. 


\section{REFERENCES}

Bache, R. J., Homans, D. C., Schwartz, J. S., and Dai, X. Z. (1988). Differences in the effects of alpha- 1 adrenergic blockade with prazosin and indoramin on coronary blood flow during exercise. J. Pharmacol. Exp. Ther. 245, 232-237.

Britton, S. L., Metting, P. J., Ronau, T. F., Strader, J. R., and Weldy, D. L. (1985). Autoregulation of hind-limb blood flow in conscious dogs. J. Physiol. (Lond.) 368, 409-422.

Casey, D. P., and Joyner, M. J. (2009a). NOS inhibition blunts and delays the compensatory dilation in hypoperfused contracting human muscles. $J$. Appl. Physiol. 107, 1685-1692.

Casey, D. P., and Joyner, M. J. (2009b). Skeletal muscle blood flow responses to hypoperfusion at rest and during rhythmic exercise in humans. J. Appl. Physiol. 107, 429-437.

Casey, D. P., and Joyner, M. J. (2011a). Contribution of adenosine to compensatory dilation in hypoperfused contracting human muscles is independent of nitric oxide. J. Appl. Physiol. 110, 1181-1189.

Casey, D. P., and Joyner, M. J. (2011b). Local control of skeletal muscle blood flow during exercise: influence of available oxygen. J. Appl. Physiol. 111, 1527-1538.

Casey, D. P., and Joyner, M. J. (2011c). Prostaglandins do not contribute to the nitric oxide-mediated compensatory vasodilation in hypoperfused exercising muscle. Am. J. Physiol. Heart Circ. Physiol. 301, H261$\mathrm{H} 268$.

Casey, D. P., Madery, B. D., Curry, T. B., Eisenach, J. H., Wilkins, B. W., and Joyner, M. J. (2010). Nitric oxide contributes to the augmented vasodilatation during hypoxic exercise. J. Physiol. (Lond.) 588, 373-385.

Daley, J. C. III, Khan, M. H., Hogeman, C. S., and Sinoway, L. I. (2003). Autonomic and vascular responses to reduced limb perfusion. J. Appl. Physiol. 95, 1493-1498.

Dinenno, F. A., Dietz, N. M., and Joyner, M. J. (2002a). Aging and forearm postjunctional alpha-adrenergic vasoconstriction in healthy men. Circulation 106, 1349-1354.

Dinenno, F. A., Eisenach, J. H., Dietz, N. M., and Joyner, M.
J. (2002b). Post-junctional alphaadrenoceptors and basal limb vascular tone in healthy men. J. Physiol. (Lond.) 540, 1103-1110.

Frewin, D. B., and Whelan, R. F. (1968). The mechanism of action of tyramine on the blood vessels of the forearm in man. Br. J. Pharmacol. Chemother. 33, 105-116.

Gonzalez-Alonso, J., Mortensen, S. P., Dawson, E. A., Secher, N. H., and Damsgaard, R. (2006). Erythrocytes and the regulation of human skeletal muscle blood flow and oxygen delivery: role of erythrocyte count and oxygenation state of haemoglobin. J. Physiol. (Lond.) 572, 295-305.

Granger, H. J., Goodman, A. H., and Granger, D. N. (1976). Role of resistance and exchange vessels in local microvascular control of skeletal muscle oxygenation in the dog. Circ. Res. 38, 379-385.

Jones, R. D., and Berne, R. M. (1964). Intrinsic Regulation of Skeletal Muscle Blood Flow. Circ. Res. 14, 126-138.

Koch, L. G., Strick, D. M., Britton, S. L., and Metting, P. J. (1991). Reflex versus autoregulatory control of hindlimb blood flow during treadmill exercise in dogs. Am. J. Physiol. 260, H436-H444.

Laprad, S. L., Augustyniak, R. A., Hammond, R. L., and O'leary, D. S. (1999). Does gender influence the strength and mechanisms of the muscle metaboreflex during dynamic exercise in dogs? Am. J. Physiol. 276, R1203-R1208.

Laxson, D. D., Dai, X. Z., Homans, D. C., and Bache, R. J. (1989). The role of alpha 1- and alpha 2-adrenergic receptors in mediation of coronary vasoconstriction in hypoperfused ischemic myocardium during exercise. Circ. Res. 65, 1688-1697.

Mark, A. L., Victor, R. G., Nerhed, C., and Wallin, B. G. (1985). Microneurographic studies of the mechanisms of sympathetic nerve responses to static exercise in humans. Circ. Res. 57, 461-469.

Metting, P. J., Weldy, D. L., Ronau, T. F., and Britton, S. L. (1986). Effect of aminophylline on hindlimb blood flow autoregulation during increased metabolism in dogs. J. Appl. Physiol. 60, 1857-1864.
Michikami, D., Kamiya, A., Qi, F., Niimi, Y., Iwase, S., and Mano, T. (2000). Arm elevation enhances muscle sympathetic nerve activity during static exercise. Environ. Med. 44, 46-48.

Mittelstadt, S. W., Bell, L. B., O’hagan, K. P., and Clifford, P. S. (1994). Muscle chemoreflex alters vascular conductance in nonischemic exercising skeletal muscle. J. Appl. Physiol. 77, 2761-2766.

Ogoh, S., Fadel, P. J., Nissen, P., Jans, O. Selmer, C., Secher, N. H., and Raven, P. B. (2003). Baroreflex-mediated changes in cardiac output and vascular conductance in response to alterations in carotid sinus pressure during exercise in humans. J. Physiol. (Lond.) 550, 317-324.

O'leary, D. S., and Sheriff, D. D. (1995). Is the muscle metaboreflex important in control of blood flow to ischemic active skeletal muscle in dogs? Am. J. Physiol. 268, H980H986.

Ping, P., and Johnson, P. C. (1992). Role of myogenic response in enhancing autoregulation of flow during sympathetic nerve stimulation. Am. J. Physiol. 263, H1177-H1184.

Rubanyi, G. M., Romero, J. C., and Vanhoutte, P. M. (1986). Flowinduced release of endotheliumderived relaxing factor. Am. J. Physiol. 250, H1145-H1149.

Savard, G., Strange, S., Kiens, B., Richter, E. A., Christensen, N. J., and Saltin, B. (1987). Noradrenaline spillover during exercise in active versus resting skeletal muscle in man. Acta Physiol. Scand. 131, 507-515.

Sheriff, D. D., Wyss, C. R., Rowell, L. B. and Scher, A. M. (1987). Does inadequate oxygen delivery trigger pressor response to muscle hypoperfusion during exercise? Am. J. Physiol. 253, H1199-H1207.

Stainsby, W. N. (1962). Autoregulation of blood flow in skeletal muscle during increased metabolic activity. Am. J. Physiol. 202, 273-276.

Victor, R. G., Bertocci, L. A., Pryor, S. L., and Nunnally, R. L. (1988). Sympathetic nerve discharge is coupled to muscle cell $\mathrm{pH}$ during exercise in humans. J. Clin. Invest. 82, 1301-1305.
Victor, R. G., Seals, D. R., and Mark, A. L. (1987). Differential control of heart rate and sympathetic nerve activity during dynamic exercise. Insight from intraneural recordings in humans. J. Clin. Invest. 79, 508-516.

Wesseling, K. H., Jansen, J. R., Settels, J. J., and Schreuder, J. J. (1993). Computation of aortic flow from pressure in humans using a nonlinear, threeelement model. J. Appl. Physiol. 74, 2566-2573.

Wilkins, B. W., Schrage, W. G., Liu, Z., Hancock, K. C., and Joyner, M. J. (2006). Systemic hypoxia and vasoconstrictor responsiveness in exercising human muscle. J. Appl. Physiol. 101, 1343-1350.

Wyss, C. R., Ardell, J. L., Scher, A. M., and Rowell, L. B. (1983). Cardiovascular responses to graded reductions in hindlimb perfusion in exercising dogs. Am. J. Physiol. 245, H481H486.

Zamir, M., Goswami, R., Salzer, D., and Shoemaker, J. K. (2007). Role of vascular bed compliance in vasomotor control in human skeletal muscle. Exp. Physiol. 92, 841-848.

Conflict of Interest Statement: The authors declare that the research was conducted in the absence of any commercial or financial relationships that could be construed as a potential conflict of interest.

Received: 21 May 2012; accepted: 26 June 2012; published online: 18 July 2012. Citation: Casey DP and Joyner MJ (2012) $\alpha$-Adrenergic blockade unmasks a greater compensatory vasodilation in hypoperfused contracting muscle. Front. Physio. 3:271. doi: 10.3389/fphys.2012.00271

This article was submitted to Frontiers in Exercise Physiology, a specialty of Frontiers in Physiology.

Copyright (C) 2012 Casey and Joyner. This is an open-access article distributed under the terms of the Creative Commons Attribution License, which permits use, distribution and reproduction in other forums, provided the original authors and source are credited and subject to any copyright notices concerning any third-party graphics etc. 